\title{
Estrategias de gestión de la paternidad dañada en varones víctima de violencia de pareja
}

Management strategies of damaged fatherhood in males who have been victims of intimate partner violence

\author{
Laia Folguera \\ Departamento de Sociología y Análisis de las Organizaciones. Universidad de Barcelona (España) \\ laiafolguera@ub.edu \\ Jordi Caïs \\ Departamento de Sociología y Análisis de las Organizaciones. Universidad de Barcelona (España) \\ jcais@ub.edu
}

\author{
CUERPOS, SEXUALIDADES Y PODER \\ MONOGRÁFICO COORDINADO POR JOSÉ MARÍA VALCUENDE. Universidad Pablo de Olavide (Sevilla).
}

\begin{abstract}
RESUMEN
En los últimos años se ha producido en España un cambio de actitud en lo que se refiere a las dinámicas de un ejercicio de paternidad participativa en el marco de un nuevo modelo de masculinidad. Esta actitud se hace particularmente significativa, desde el punto de vista del estudio del género, en el colectivo de varones heterosexuales que dicen verse afectados por violencia a manos de su pareja. A partir de entrevistas en profundidad a estos varones, este estudio explora cómo la paternidad ha tomado relevancia en tanto que elemento legitimador de la situación de victimización. El artículo analiza también cómo estos varones maltratados gestionan la invisibilidad del fenómeno y los condicionantes de su capacidad de expresión pública.
\end{abstract}

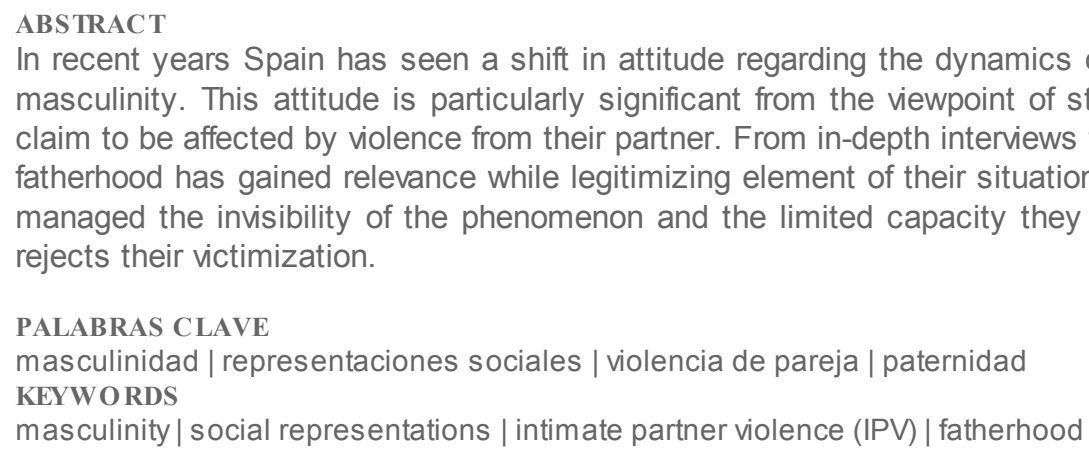
rejects their victimization.

PALABRAS CLAVE

masculinidad | representaciones sociales | violencia de pareja | paternidad

KEYWORDS

masculinity | social representations | intimate partner violence (IPV) | fatherhood masculinity. This attitude is particularly significant from the viewpoint of studying gender in the group of heterosexual men who claim to be affected by violence from their partner. From in-depth interviews that convey their experiences, this study explores how fatherhood has gained relevance while legitimizing element of their situation of victimization. The article analyses how these men managed the invisibility of the phenomenon and the limited capacity they have to express their position in an environment that

\section{Introducción}

El varón como víctima en el seno de las relaciones de pareja se distancia de la "norma" de lo aceptado socialmente. Sin embargo, el estudio de varones heterosexuales maltratados por sus mujeres ayuda a dar luz a nuevos aspectos de la violencia en el ámbito de la pareja. Su invisibilidad, en este caso, no solo se debe a que afecta a la más estricta intimidad del individuo sino también a que existen una serie de connotaciones sociales y culturales que pesan sobre las víctimas de este tipo de violencia. El presente estudio se enmarca en el contexto español en donde existe una nula producción de estudios académicos sobre violencia femenina hacia varones. En España ha prevalecido la imagen del concepto del honor asimilado a la hombría y a la preeminencia social enarbolado en el período franquista. La figura del "varón maltratado" permite estudiar la gestión de la identidad masculina. Ello es debido a que, en estos casos, la variable género ha emergido como parte de la gestión identitaria de estos varones y les obliga a repensar las implicaciones de la masculinidad hegemónica en su contexto inmediato. El entorno sociocultural no es propicio a aquel varón que confiese haber sido agredido por parte de su pareja femenina. La imagen, consciente o inconsciente, de "macho ibérico" implica determinadas connotaciones: evitar mostrar los sentimientos, evitar llorar en público, evitar presentarse como víctima. Los varones objeto de análisis se encuentran ante un discurso social al que no pueden adherirse. Por ello, se ven obligados a construir unas 
estrategias identitarias de adaptación.

En este contexto podemos preguntamos, ¿cómo procesan los varones la experiencia de la violencia en las relaciones de pareja, en el ámbito heterosexual, cuando son ellos los receptores?, ¿cómo gestionan las reacciones sociales ante su situación de "víctima"?, ¿qué estrategias compensatorias tienen a su alcance? El centro aquí es el estudio de la gestión que estas personas hacen de su vida diaria, y de las estrategias que utilizan para solventar sus conflictos en una sociedad que rechaza la posibilidad de su victimización. Hemos detectado tres ejes básicos de atención analítica: en primer lugar, cómo los varones maltratados gestionan la invisibilidad del fenómeno; en segundo lugar, las consecuencias de la "masculinidad" que derivan en la incapacidad de estos varones para expresar públicamente una situación que puede resultar "vergonzosa" y "humillante" y, por último, el esfuerzo de estos varones maltratados para redefinir y posicionarse en el discurso hegemónico del género. En todos estos aspectos, las estrategias de adaptación y de gestión de las emociones en un contexto diario adverso aportan importantes elementos de reflexión sociológica en torno al género y a la emergencia de las nuevas masculinidades.

El discurso de los varones entrevistados en este estudio está inmerso en las representaciones sociales del entorno como "una forma de conocimiento que los sujetos crean bajo la influencia de las formas de pensamiento y normas colectivas de comportamiento integrándolas en las prácticas rutinarias y en la experiencia inmediata" (Jodelet 1984: 214). Esas representaciones requieren la referencia al "imaginario social" (Anzieu 1981) como categoría clave para la interpretación de la producción de creencias e imágenes colectivas. Así mismo, sus experiencias se mueven entre estereotipos entendidos como "creencias cognitivas sobre las diferencias entre hombres y mujeres que los participantes comparten con los miembros de su cultura" (Best 2004: 11) que se (re)producen junto con el avance de la sociedad y bajo la necesidad de adaptación para estructurar la identidad personal.

\section{Enfoque metodológico}

El lector detectará en este estudio un diseño marcadamente exploratorio a un campo poco o nada estudiado de forma académica en el ámbito español. Este diseño exploratorio tiene consecuencias en la formulación de las conclusiones. Así, se tiene en cuenta que esta investigación abre un campo de estudio del cual no deben extraerse conclusiones precipitadas a modo de conclusiones. Para la consecución de los objetivos, se ha adoptado una metodología cualitativa. El interés recae en el análisis de experiencias vitales y de representaciones sociales en torno a las mismas. Son áreas que no aceptan medición numérica. Este estudio se basa en una serie de entrevistas a varones supuestamente heterosexuales que afirman sufrir o haber sufrido violencia física y/o psicológica por parte de una mujer. El guión de las entrevistas se estructura en relación a la definición del sujeto y de su entorno más próximo, la percepción de las vivencias de su relación de pareja y el relato de los tipos de violencia, la capacidad de expresión pública del sujeto y la gestión de las reacciones de su entorno, así como su relación con el ámbito judicial. De este guión, las referencias a la paternidad han emergido con fuerza una vez inmersos en el propio relato.

La consecución de la muestra es fruto de un trabajo de campo previo de más de dos años. En este tiempo, se han realizado varias entrevistas en las cuales se ha hecho un seguimiento en profundidad a diez sujetos escogidos por varios criterios: validez teórica, grado de voluntad de participar en el proyecto y disposición a compartir documentos personales. Esta posibilidad de seguimiento de los entrevistados permite profundizar en sus vivencias, ayuda a matizar la complejidad del tema tratado y minimiza la dificultad de expresión del conflicto en el primer encuentro. Las primeras entrevistas empezaron con la técnica de la bola de nieve y mediante la búsqueda de casos que algunos varones habían hecho públicos en medios de comunicación públicos o en foros de internet. El perfil de los entrevistados es de entre treinta y sesenta años y de diversa clase social y tipo de profesión. Se ha contactado con varones de diversas áreas geográficas de España, pero la mayor parte son residentes en Cataluña. Los varones entrevistados tienen hijos menores de edad en el momento de la primera entrevista. La intención inicial era entrevistar tanto a varones con hijos/as como aquellos que no los tuvieran, pero las circunstancias han hecho que los varones entrevistados sean padres. Ello es debido a que el elemento de reivindicación legitimadora que ofrece la paternidad y la "protección" de los hijos/as ha actuado en su voluntad de visibilización. Por tanto, una de las peculiaridades de los varones entrevistados es que todos tienen hijos/as, y la mayoría, en el momento del primer contacto, menores de edad. Este es un factor que crea un vínculo emocional que liga a la persona y añade un elemento de reivindicación social. Así mismo, a nivel metodológico, condiciona en cierto sentido la interacción con el 
entrevistador al permitir utilizar la paternidad como "coletilla discursiva" en momentos comprometidos.

\section{Marco de referencia}

Los estudios en los que el varón se presenta como víctima de violencia en relaciones de pareja heterosexual no despiertan, en el ámbito académico, el interés de la violencia ejercida sobre otros colectivos (mujeres, ancianos/as o niños/as). Pero varios estudios han abordado este problema ya sea exclusivamente a nivel de reflexión teórica y revisión de investigaciones (Dutton 2007, George 2007, Graham-Kevan 2007, Hines y Malley-Morrison 2001, Marshall 1992, entre otros), como mediante estudios prácticos recurriendo tanto a metodología cuantitativa (Fiebert y González 1997, Sommer 1994, McLeod 1984), cualiatitva (Durfee 2011, O'Connal 2006) o mixta (Cook 1997, Gregorash 1993, Straus y otros 1980, Steinmetz 1977, Gelles 1974). La existencia de estos estudios a nivel internacional contrasta con la carencia de estos en España.

El caso español es interesante, no solo por la nula producción de estudios académicos sobre la problemática del "varón víctima", sino porque en España ha prevalecido con fuerza el ideal de masculinidad hegemónica que limita la aceptación social de este colectivo. En lo que atañe a los estudios sobre el área mediterránea, Julian Pitt-Rivers, en su obra Honor and Shame: The values of Mediterranean Society (1965), consideró que el honor asumía en los países mediterráneos un papel conformador de las estructuras sociales. La obra de David Gilmore Manhood in the Making (1990) empieza en Andalucía ya que, según él, es una de las zonas más conservadoras de España con fuerte referente a un "modelo ideal" de masculinidad. En la España franquista, el nacionalismo enarbolado con el lema "Todo por la patria" y la idea de "Muerte, sacrificio y honor" representan a la perfección el ideal de masculinidad hegemónica. La concepción del héroe es un ejemplo del exponente de la masculinidad hegemónica y es que el héroe es un "varón que produce y reproduce, que está en la cima de lo socialmente prescrito, y que por ello espera recibir los parabienes sociales que reconozcan sus logros" (Guasch 2006: 45).

Pese a la permanencia de los roles asociados a la masculinidad hegemónica, en España, el cambio del ideal masculino se ha acelerado hacia finales del siglo XX (Gil Calvo 1997). Un reflejo de este cambio se observa en la evolución de los roles de género en el ámbito familiar. Algunas tesis (Caïs 2012, Meil 2006) apuntan a que la familia española se está reestructurando debido a que las circunstancias sociales y económicas en las que se mueve han cambiado y se ha hecho necesario re-negociar los roles de sus miembros. Hoy en día la mayoría de familias españolas necesita dos sueldos para sobrevivir. La mujer española ya no es socializada para ejercer el rol de ama de casa que se le suponía hace años, tiene una formación igual o superior a la del hombre que le ha permitido incorporarse al mercado de trabajo. Todo ello afecta a las estrategias de cuidado entre los miembros de la familia y a la gestión del contrato intergeneracional (Caïs y Folguera 2013, Sarasa y Billingsley 2008). Es en este espacio en dónde los varones deben gestionar su identidad para adaptarse a las nuevas exigencias de la sociedad de referencia.

Las profundas transformaciones sociales de la posmodernidad han conllevado la revisión, aunque sólo sea a nivel teórico, de un modelo masculino tenido como referencial e intocable. Los cambios culturales han influido en la concepción de las relaciones de poder dentro de la pareja. No solo el varón dedica cada vez más tiempo a las tareas del hogar y al cuidado de los hijos, sino que la sociedad le exige cada vez más esta implicación, tanto en términos morales como de viabilidad económica. El modelo de masculinidad hegemónica se diluye fruto de este proceso de transición al que los varones deben adaptarse. Los avances sociales se observan también en la aparición de actitudes reivindicativas en torno al género por parte de los varones. El movimiento de varones nació hacia finales de la segunda ola del feminismo en la que los varones empiezan a preguntarse sobre su proceso de socialización, sobre cómo han sido educados para "ser un hombre" y lo que comporta todo ello. En la década de los ochenta se empieza a gestar, pues, la idea de que el sexismo ya no es solo un problema de mujeres y que los varones, mediante el cambio de actitudes

y la acción reivindicativa, pueden formar parte activa del movimiento. Estos avances a nivel internacional llegan a España con el resurgimiento del feminismo en la etapa de la transición franquista. Algunas ramas del movimiento feminista actual plantean también la necesidad de tener en cuenta al varón en el seno de sus reivindicaciones. ¿Hay un "nuevo varón" dispuesto a participar en la lucha por la igualdad? Aunque la respuesta parece ser afirmativa, en un sistema de relaciones -en este caso de genero-, el cambio de una de las partes conlleva la adaptación de la otra y de los elementos que la sustentan, a nivel individual y a nivel social. 
Las asociaciones de hombres igualitarios son representativas de un movimiento que reflexiona sobre las "nuevas masculinidades" y abogan por construir un modelo de varón que sea capaz de apartar los símbolos de poder, agresividad y control de las emociones. En España, los primeros grupos de varones aparecen en Sevilla y Valencia en 1985, si bien de forma reducida. Pero son un ejemplo para un movimiento de hombres por la igualdad que se va extendiendo y consolidando en la España actual. Otra asociación de referencia para el movimiento en España es la Asociación de Hombres lgualitarios, AHIGE, que tiene como uno de sus lemas "aprender nuevas formas de ser hombre". Esta asociación nace en 2001 en Málaga "con la necesidad de dar dimensión social a los cambios y vivencias que estábamos experimentando" (1). El objetivo primero que exponen en su web es el de "trabajar contra la discriminación estructural que esta sociedad machista genera (básicamente sobre las mujeres y personas no heterosexuales) y favorecer el cambio de los hombres hacia posiciones igualitarias". El éxito de esta asociación, con planteamientos y organización inspirada en los Grupos de Hombres pro-feministas de los años 80, es otra muestra del giro que está tomando la sociedad española con respecto a la representación de la imagen del varón y de la masculinidad ideal.

A mediados de la década de los 90 emergen otros colectivos de varones que, apostando también por la igualdad de genero, pero con otro discurso de fondo, reclaman que se les reconozca la posibilidad de que ellos también puedan ser víctimas de malos tratos en el seno de la pareja. Son colectivos que, aunque con reivindicaciones diferentes, se unen principalmente bajo reivindicaciones jurídicas. Sus pretensiones, entre ellas el reconocimiento de su rol como padre y la voluntad de ejercer como tal, así como sus estrategias organizativas, también contribuyen a poner de relieve otra dimensión de los modelos de masculinidad y de representación del varón en el ámbito doméstico. La reivindicación del rol en el ámbito familiar se observa en su denominación: "Asociaciones de padres por la custodia compartida" o "Asociaciones de padres separados". Es un fenómeno reciente indicativo de una situación social compleja. Los cambios acaecidos en las últimas décadas en relación a la redefinición del rol de la mujer y del varón, así como de la familia en su conjunto, influyen en otros aspectos de la vida social y afectan a la forma en que las personas piensan y definen su entorno. El volumen de estas asociaciones ha crecido, desde los años 90 , de forma exponencial llegando a contar ahora con más de cien sedes repartidas en el territorio español.

Pese a los indicios de cambio del rol del varón en la sociedad española, las referencias a la sociedad patriarcal se asientan como las causantes de la violencia hacia la mujer en el ámbito de la pareja. En España, la Ley de Violencia de Género de 2004 define la violencia de género como "la expresión de una situación de desigualdad en el ámbito de las relaciones que implican la construcción de las expectativas asociadas al género (...). La violencia de género no es un problema que afecte al ámbito privado. Al contrario, se manifiesta como el símbolo más brutal de la desigualdad existente en nuestra sociedad. Se trata de una violencia que se dirige sobre las mujeres por el hecho mismo de serlo". La ley española vincula de forma directa la violencia de género a los presupuestos de masculinidad en estructuras patriarcales.

Queremos remarcar aquí que hay unas distinciones entre violencia de género, violencia doméstica y violencia de pareja que es relevante tener en cuenta en el contexto de estudio que se plantea en estas páginas. Existen diferentes formas terminológicas de abordar aquella violencia que se da en el ámbito privado y en la que entran en juego los roles de género (violencia de género, sexista o machista entre otras). La violencia doméstica es aquella que se da específicamente en el ámbito del hogar, ejercida sobre aquellos que ostentan una debilidad especial: ancianos, mujeres y menores. Debemos preguntarnos si, atendiendo a la definición institucional de violencia de género presentada en el párrafo anterior, la violencia que puedan sufrir los varones por parte de una mujer puede tener cabida bajo esta clasificación. Este tipo de violencia no se produce por "una desigualdad existente en nuestra sociedad". Aunque se ha comprobado que los varones entrevistados aquí se sienten victimas por razón de género (que no de violencia de género), ya que su capacidad de expresión está condicionada por los presupuestos en torno a la masculinidad, creemos más oportuno hablar de violencia en el ámbito de la pareja (Intimate Partner Violence).

\section{Explicaciones de la invisibilidad del fenómeno del varón maltratado}

La violencia perpetrada por mujeres hacia varones en las relaciones de pareja heterosexual ha sido un tema tabú desde hace décadas (Dowd 2001, George 2007). Philip W. Cook publica en el año 1997 lo que podríamos llamar el primer libro que trata de forma exclusiva la violencia hacia el varón. El título del libro es explícito, Abused Men: The Hidden Side of Domestic Violence. Hay varios argumentos que intentan 
explicar el porqué se ha estudiado tan poco la violencia hacia el varón. El primero es el escaso número de víctimas varones de violencia de género comparado con el número de víctimas mujeres. Algunos autores apuntan que el ocultamiento social y el olvido académico se explica en parte por el hecho del predominio de la sociología feminista y de la queer theory (George 2007). Otros afirman que la atribución de la fuerza física del varón actúa invisibilizando la posibilidad de ser reconocidos y de presentarse como víctimas (Cook 1997) o que, en todo caso, la violencia que puedan recibir corresponderá a minor assaults (Morse 1995) o estará centrada en agresiones psicológicas y no físicas (Hines y Malley-Morrison 2001). Existe la creencia de que los varones son -y deben ser- capaces de defenderse por sí mismos y hay ciertas reticencias en aceptar la violencia femenina. Los estereotipos sociales asociados a la masculinidad -el varón debe ser fuerte, agresivo y menos vulnerable que la mujer- y el debate en torno al "Myth of Male Power" (Farrell 1994) también actúan en la falta de reconocimiento del fenómeno (Steinmetz 1977, George 1994, Cook 1997, Down 2001). Estos estereotipos asociados a los roles de género actúan a su vez, a nivel individual, para motivar al varón a ocultar una agresión por parte de una mujer (Hines y Malley-Morrison 2001, Straus 1999, Steinmetz 1977). Existe el miedo a mostrar debilidad o a sentir que se les mirará con desconfianza por afirmar algo que parece difícil de creer.

Pese a la falta de atención académica y a la invisibilidad social del fenómeno, en España ha habido un aumento de denuncias por parte de varones. Según datos del Ministerio del Interior, en 2002, 8.216 varones denunciaron haber sufrido "malos tratos producidos por pareja o ex-pareja", mientras que en 2007 la cifra asciende a 10.092 (INE 2008 y 2009) (2). En los medios de comunicación también se ha observado un aumento en la presencia de casos de varones que afirmaban haber sido maltratados por su mujer. Ya sea prensa escrita o programas de televisión, han presentado algunos de estos casos como una "rareza" que puede llamar la atención del público. Como ejemplo encontramos una noticia publicada en el periódico El País que refuerza esta idea de "rareza" y "excepcionalidad": "Pocos, pero también víctimas: 32 varones han muerto a manos de su pareja, femenina o masculina, en los últimos cinco años (...). Son la excepción que confirma la regla. Pero están ahî" (Prades 2012). Ya en el título, el adverbio "también" actúa como un recordatorio inclusivo a constatar que existen y alude a su vez a la comparación con la situación de la mujer víctima. La noticia anuncia su existencia pero introduce en la primera línea del redactado la palabra "excepción". Las acciones del movimiento asociativo que conforman las Asociaciones de Padres Separados en el territorio español ha actuado como potenciador de la presencia de los varones maltratados en los medios de comunicación. Su discurso ha generado controversia entre el movimiento feminista y parte de la ciudadanía, al percibirse como un ataque a los logros en relación a la protección de la mujer en casos de malos tratos.

Algunos de los varones entrevistados en el presente estudio han optado por usar los media para visibilizar sus casos. Paco es un varón de 50 años residente en Barcelona, y con dos hijas, que afirma haber sufrido violencia física y psicológica. Su exmujer ha sido inculpada "como autora de un delito de lesiones en violencia familiar" y condenada a tres meses de prisión. Su caso ha salido en los medios de comunicación que lo presenta como una rareza dentro del marco de la violencia en las relaciones de pareja en el ámbito heterosexual. El título del documental es lo suficientemente explícito: "Caso de excepción". El periodista afirma que "pese a que la violencia de género se ejerce básicamente sobre las mujeres, existe una realidad minoritaria: la de los varones maltratados. Paco es de los pocos que se atreve a denunciarlo abiertamente (...). Aunque más del noventa por ciento de personas muertas a manos de su pareja son mujeres, también hay otro colectivo, el de hombres maltratados, que hoy por hoy son invisibles en nuestra sociedad." (3) En estas frases se está apuntando a una de las posibles causas de la invisibilización de este fenómeno: el hecho de que el porcentaje sea menor que la violencia ejercida hacia la mujer. Encasillarse en una "realidad minoritaria" implica que estás, dentro de la excepcionalidad de la condición de víctima, en una situación que se aparta de lo que es considerado "normal" o aceptado en el imaginario social.

El caso de Ramón, otro de los entrevistados que declara haber sufrido violencia física y psicológica por parte de la que ahora es su exmujer, fue reproducido en el Diario de Mallorca en tres ocasiones: "Tengo miedo de mi mujer" (4) (2008); "Mi mujer tiene licencia para pegarme" (5) (2009) y "Un hombre en terapia para maltratadas" (6) (2012). Una cadena local también entrevistó a Ramón en 2012 para reflexionar sobre la diferencia en la magnitud de casos de violencia hacia el varón y hacia la mujer. Se iniciaba la entrevista con la siguiente observación: "La violencia de género es un problema muy grave que afecta a nuestra sociedad y en la gran mayoría de casos son agresiones de hombres hacia mujeres. Pero también existe el caso contrario. Hombres agredidos por sus mujeres" (7). El argumento de la importancia de la violencia hacia la mujer debido al número de víctimas y a las estructuras sociales que la propician es una idea que ha 
calado hondo en el imaginario social español. Potencia la invisibilidad del fenómeno y revierte en percepción de excepcionalidad.

Los varones entrevistados desarrollan estrategias de legitimación para contrarrestar la falta de interés que creen que muestra la sociedad hacia su problemática. Intentan demostrar la veracidad de su caso porque sienten que se escapa de la normalidad. Para gestionar el problema de la excepcionalidad, los varones entrevistados explican casos de conocidos suyos o de casos que han sabido a través de los medios de comunicación. Algunos tienen un archivo de noticias de periódico en el cual recogen ejemplos en los que la mujer es la agressora, y no dudan en mostrar pruebas (fotografías, grabaciones de escuchas telefónicas o documentos judiciales) que legitimen y den credibilidad a su posición de vícitma.

El "varón maltratado" reacciona ante el hecho de encontrarse en el lado opuesto de las expectativas de lo que debe ser un hombre (dominación, poder y control). Este sentimiento conduce a la vergüenza que, como ya apuntó Helen Lewis en 1971, es un concepto eminentemente social. Y la vergüenza actúa como silenciador de la capacidad de expresión pública que tiene estos varones (Hines y Malley-Morrison 2001). "Vergüenza", "orgullo", "honor" (o sensación de pérdida del mismo) son elementos que sirven de guía de comportamiento y acción, pero que deben ser gestionados sin ser manifiestos o evidentes. Así lo afirman también los estudios de Helen Lewis (1971), de Philip W. Cook (1997) o de Tomas Scheff (2003) apuntando a la necesidad de buscar correlatos discursivos al hablar de ella. Ello se constata en que todos los varones entrevistados para el estudio evitaron utilitzar la palabra "vergüenza" excepto Ramón. Este varón se refiere a la gestión de sus propios sentimientos de la siguente manera:

"Creo que hay muchos hombres que no denunciarían los malos tratos debido al orgullo de no querer decir que 'mi mujer me pega'. Yo he sentido vergüenza de salir de mi casa. Salir a la calle, mirar a un lado, ver al vecindario y volver a entrar en casa. Sentía vergüenza porque dentro de casa ella me había dicho de todo y se oía todo. Sientes vergüenza y te sientes humillado. Esto no te lo va a quitar nadie. De hecho, si vas a la policía a saber lo que te vas a encontrar. Yo he oído a mujeres diciendo: ¡qué! ¿este es un hombre maltratado? ¡No existe el hombre maltratado!” (Ramón (8)).

En este extracto observamos que Ramón, al hablar de las posibles causas de un ocultamiento por vergüenza, une la sensación de no cumplir con el rol que se espera de un hombre, con la desprotección policial y judicial que siente. El honor masculino, como sentimiento de la propia dignidad asociado al orgullo, actúa disminuyendo la capacidad de expresión pública de un hecho que escapa a la norma social. Otra problemática es el apoyo mayor o menor que se puede encontrar en los círculos familiares o de las amistades. Los varones maltratados deben gestionar las reacciones ante sus relatos. En el caso de Ángel, un varón con buena posición económica y social, solo encontró apoyo "a nivel familiar". Ángel centra su discurso en la violencia psicológica y en las amenazas que supuestamente recibía por parte de su mujer. Sus amigos se sorprenden de conocer su situación pero en cambio su familia le apoya: "Mis amigos se quedaban con la boca abierta de lo que les explicaba. Es que a veces parece que el macho como que no puede explicarlo. Pero yo lo explicaba a la familia y ellos sí que me apoyaban" (Ángel (9)).

Ángel, al igual que otros varones que han hecho pública su posición de víctima, ha debido hacer frente a reacciones burlescas o de descrédito por parte del "Otro". En este caso, Ángel afirma explícitamente que la reacción de incredulidad de su entorno de amigos fue debida a los presupuestos de la masculinidad: el "macho". El imaginario social dificulta al varón presentarse como víctima no solo ante el entorno social más próximo sino también ante las instituciones que en teoría le amparan (Stets y Straus 1990, Dutton 1988, Edleson y Brygger 1986). En el caso de Alberto, que acudió a servicios sociales, relata la reacción de mofa con la que se encontró:

"Los hay que se enteran más que otros sobre este tema (...). Mira, por ejemplo, el día que fui a hacer el parte de lesión física, viene una empleada, me ve la herida en la frente y me pregunta qué ha pasado. Le contesté 'mi mujer me ha pegado'. Y se puso a reír. Yo me quedé serio y entonces ella también. Me dijo: perdona, es que pensaba que era broma" (Alberto (10)).

Alberto, al igual que percibió un descrédito social al acudir a instituciones públicas de protección, tuvo también temor de provocar las burlas de sus amigos cuando conocieran su situación como víctima. Cuando se le pregunta directamente si contaba su situación ante su entorno más próximo, Alberto responde:

"Yo se lo comentaba a mis padres, a mi amigo más íntimo... y prácticamente a nadie más. Porque, 
¿qué haces?, ¿qué dices? Tus amigos te van a consolar pero luego se van a reír cuando gires la esquina. Mira... cuando te ha pasado algo en la vida... y tú lo cuentas, pero no es normal y resulta chocante, se te van a reír y como me apures jen la cara!" (Alberto).

Los propios varones maltratados se definen como casos excepcionales debido a que consideran que no encajan con los del imaginario colectivo cuando se habla de violencia de género o de violencia doméstica. La excepcionalidad de la experiencia que viven tiene consecuencias en su (in)capacidad de expresión pública. Temen no ser comprendidos. Así, expresiones tales como “¿Sabes lo que te quiero decir?” o "¿Entiendes?" alternan con alusiones a la complejidad de la vivencia y a la dificultad de encontrar una transmisión que sea inteligible para el interlocutor: "Es que es un tema muy complejo", "es que es más complicado de lo que tú te crees, hasta que no te encuentras con ello...", "es que no sé cómo explicártelo. Se me hace difícil articular un orden". La dificultad de "comunicar lo incomunicable" debe gestionarse desde múltiples ámbitos. La mayoría de los varones entrevistados han eludido en su momento expresar las experiencias sufridas por la reticencia a mostrar una imagen social no deseada. Y, en aquellos casos que dicen no verse condicionados por la imagen pública, afirman que a "otros" varones, en su misma situación, sí que les condicionaría.

La imagen pública preocupa a los sujetos entrevistados y condiciona su capacidad de expresión pública. Por ejemplo, a Enric, un varón que ahora cuenta con una orden de protección contra su mujer, se lo llevaron a comisaría cuando fue a buscar a su hijo a casa de su mujer. Según él, su pareja le había denunciado por amenazas y al llegar Enric la policía le estaba esperando. Pero Enric afirma que era él quien tenía temor a acercarse a su mujer. Así es como relata las consecuencias que pudo tener este hecho para su imagen pública: "Te ha visto todo el barrio. Ellos no saben por qué se te han llevado a la comisaría pero piensan siempre en el mismo motivo: porque él la ha agredido, la ha insultado..., pero a lo mejor no es asî" (Enric (11)).

En el imaginario de Enric está presente la atribución de lo que los "Otros" piensan de él ante una situación que resulta embarazosa. En su explicación, Enric recurre a una generalización socializando su experiencia: "el motivo siempre es el mismo, que él la ha agredido". Enric prioriza la importancia de la imagen pública en su entorno más cercano ("Primero que te ha visto todo el barrio") que actúa como referente de control social próximo. Afirma que, aunque los vecinos no saben por qué se lo llevan a comisaría, están pensando ya en él como un maltratador.

\section{La paternidad como elemento legitimador de la situación de víctima de los varones maltratados}

Los varones maltratados desarrollan una estrategia básica que les ayuda a hacer visible su situación: las referencias constantes a la paternidad. Paco afirma que "He sido un hombre maltratado. He sido maltratado físicamente y psicológicamente, pero lo que me hace sufrir más es el maltrato persistente de la justicia que me ha separado de mis hijas" (12). Alberto afirma que se siente maltratado "sobre todo por el maltrato que están sufriendo mis hijas" (13) y Enric afirma que, aparte de sentirse un "hombre maltratado", también es "un padre maltratado" (14). Cuando Enric habla de reconocer su posición como víctima desarrolla esta idea:

"Sí. Psicológicamente sí. Ha llegado un momento en que mis amigos me han abierto los ojos y me han concienciado de que sí. De que soy un padre maltratado psicológicamente. Sí. (...). He ido al servicio de Atención a la Víctima y me han lo han dicho. He ido a los Mossos de Esquadra y me lo han dicho. Por la madre de mi hijo. Y hasta que lo he aceptado pues ha pasado el tiempo. Quizás demasiado tiempo. Pero sí. Debo reconocerlo. Después de ocho años debo reconocer que soy un padre maltratado psicológicamente por la madre de mi hijo. Y no sólo psicológicamente" (Enric).

Enric relaciona su maltrato con el referente de su paternidad. Pone más énfasis en ser un "padre maltratado" que un "hombre maltratado". Hay que hacer notar también que la figura de la cual él recibe la agresión la define como "la madre de mi hijo" y no como su expareja. De hecho, la gestión de algunos ítems que conforman su masculinidad, entre ellos la paternidad, les ofrecen también un marco de protección ante el descrédito social. Para los varones objeto de estudio, el género se ha convertido en un objeto de reflexión a partir de la experiencia vivida. Ha habido un proceso de toma de consciencia de su rol en las relaciones de género que antes les podía pasar desapercibida o que, en todo caso, no estaba presente en el día a día de su discurso identitario. Dicha concienciación de género aparece en el proceso de victimización, en la 
dificultad de expresar sus emociones en el momento de relatar las experiencias vividas, y al tratar de conseguir un capital social.

La percepción de una mayor o menor vulnerabilidad condiciona las reacciones del entorno ante el acto agresivo así como del estamento judicial que debe juzgarlos. En el caso de los varones, la atribución de una fuerza física superior les impide presentarse como víctimas. Así, a nivel social, la posibilidad del varón víctima de violencia femenina en las relaciones de pareja se piensa más en términos de violencia psicológica que física (Cook 1997). Sin embargo, puede ser más operativo centrarse en las agresiones físicas ya que es una expresión de violencia más fácil de detectar que la psicológica (Straus 1999, Dutton 1995). Las agresiones físicas se valoran a nivel social y a nivel individual en función de quien las recibe y de quien las ejerce, de su gravedad, de su reiteración, de si son fruto de un estado emocional de ira puntual o de si tienen intencionalidad lesiva. Hemos localizado en el discurso de los varones dificultad de expresión, respuestas evasivas, negaciones, o minimizaciones de la importancia de las agresiones físicas. Son estrategias que permiten esconder la masculinidad dañada. En el siguiente extracto de entrevista, Emili actúa negando la agresión física sufrida convencido implícitamente de su superioridad física:

“¿Te agredió físicamente alguna vez? -se le pregunta-. No, no pudo. No la dejé. ¿Pero lo intentó? -se le pregunta-. Sí, responde (...). Me da una bofetada en la cara de prueba, muy floja. Le digo '¿pero qué haces?'. Y a continuación va la segunda bofetada un poco más fuerte y decidida. Entonces le digo 'estás muy alterada...'. Y veo venir una tercera bofetada, ésta ya en plan fuerte y decidido. Por puro reflejo la paro amarrándole la mano antes de que me llegara a la cara” (Emili (15)).

La percepción del escaso daño de las agresiones recibidas hace que Emili no las considere como violencia física. Es él quien tiene el control de la situación hasta el final de la escena relatada: "la paro amarrándole la mano". En el caso de Luis (16), un varón que afirma haberse encontrado con una relación que derivó en episodios de violencia física mutua, al hablar de una riña que acabó en un episodio violento, tampoco hace referencia a "violencia física" sino a "brotes agresivos" y a "agresión de contacto físico". Luis, al evitar usar la palabra "violencia", consciente o inconscientemente, se desmarca del universo discursivo de la violencia de género, en el que se presupone a la mujer víctima de un sistema de desigualdad en el orden de género. Está gestionando discursivamente la relativización de la gravedad de la acción y de su resultado. En el caso de Alberto (17) sucede algo parecido a nivel discursivo. Él elude decir explícitamente "me pegó" o "me agredió" y recurre a "poner la mano encima" como descripción de la agresión sufrida (18). Le cuesta verbalizar esta agresión física y al relatar estos episodios Alberto duda sobre cómo definirlos. ¿Es esto un indicador de sentimiento de vergüenza? Presuponemos que sí.

Para los varones entrevistados, no es solo la agresión física la que es importante. Las agresiones psicológicas actúan como una forma importante de percepción de victimización. Las agresiones psicológicas son un elemento más difícil de detectar y de probar que las agresiones físicas pero, ante la posible existencia de violencia psicológica, los entrevistados son más explícitos y dedican mayor parte de su discurso a relatar detalles de las mismas. Quizás ello se deba a que es un elemento menos fácil de asociar con el menoscabo de la masculinidad. En el imaginario social pesa la creencia de que la supuesta fuerza física del varón, en comparación con la de la mujer, le protege de ser víctima de agresiones físicas por parte del "sexo débil".

Las características físicas, atribuidas o reales, no siempre tienen por qué condicionar la posibilidad de victimización de una persona (ya sea mujer o varón) y, aún menos, la victimización psicológica. Juan es un varón alto, de casi metro noventa, y corpulento. Es propietario de una empresa de seguros en Barcelona y dice, remarcándolo para darle importancia, que "he llegado a cobrar hasta cinco mil euros al mes". Estas características, tanto de fortaleza física como de persona emprendedora y con posición de poder en el ámbito laboral, no le han ahorrado sentirse víctima de violencia psicológica por parte de la que fue su esposa. Así relata Juan algunas experiencias de violencia psicológica y/o moral que afirma haber sufrido:

"Cuando estabais juntos, ¿había episodios de violencia física? -se le pregunta-. No. Cero. Porque yo ya sabía cómo era. Vi cómo debía comportarme. Es decir, aceptar todo lo que ella diga y todo lo que ella quiera. $Y$ yo, tan solo intentar conseguir algún espacio en casa. (...). O te vas de casa o llamo a los mossos me decía chillando. Y yo me arrodillaba delante de ella. (...). Íbamos a casa de sus padres cada día, ¡cada día! Mi familia estaba totalmente olvidada; y mis amistades también" (Juan (19)). 
En este caso, cuando se le pregunta por si había "episodios de violencia", responde tajante que "no"; pero a continuación habla de elementos que pueden entenderse, en el marco de las relaciones de género, como indicadores de ser víctima de violencia psicológica (sumisión y control). Pese a su corpulencia física y a su profesión que lo define como una persona activa y emprendedora, parece que la relación con su exmujer fue de sometimiento continuo. En el extracto de entrevista reproducido, Juan pone de relieve una actitud de sumisión ante su mujer y de aislamiento social que esta le genera. Para evitar discusiones, Juan hacía "todo lo que ella quería".

La experiencia vivida por los varones entrevistados ha comportado una reformulación del discurso de género que se manifiesta en la interpretación y gestión de su vida diaria. Los varones maltratados utilizan la referencia a su masculinidad para desmarcarse de la "masculinidad hegemónica". Implícita y explícitamente, rechazan aquellos comportamientos socialmente mal vistos sobre el "macho" que consideran que deslegitimarían su comportamiento ante la sociedad civil. Es decir, todo aquello que se refiere al comportamiento igualitario ante las responsabilidades prácticas y familiares que comporta la vida en común. Así, por ejemplo, Juan afirma que no rehúsa hacer ningún tipo de tareas del hogar y alude a que trabajos que se consideraban antes "cosas de mujeres" él los lleva a cabo con normalidad y sin que les suponga un descrédito de su condición de varón:

"Yo nunca he querido ser como mi padre. Él era: aquí me siento y tráeme la comida, tráeme esto y lo otro... era la educación de esos años. Pero yo quise otro modelo. Si preguntas a mi hijo: ¿Has visto a tu madre planchar alguna vez?, te dirá que no. ¿Has visto a papa? Te dirá que siempre. Mi hijo ve como voy a comprar, hago la comida, plancho... las cosas que son naturales. No son cosas de mujeres, son cosas naturales" (Juan).

Lo relevante aquí no es que realicen estas tareas o no, sino el hecho de que deseen ponerlo de relieve aunque no se les pregunte por ello. Así, la paternidad y el desmarcarse de la imagen de masculinidad hegemónica ayudan a los varones entrevistados a legitimar su posición como posible víctima en violencia de pareja. Existen varias situaciones personales que permiten definir a una persona como vulnerable y, en consecuencia, limitar su capacidad de reacción a la violencia sufrida. Pero cuando la víctima es un varón, algunas de estas situaciones personales no son tenidas en cuenta. Es el caso de la dependencia económica, que no se contempla cuando se trata de un posible varón víctima. En el caso de que la víctima de violencia de pareja sea un varón también se minimiza la posible dependencia emocional. Pero la paternidad, por ejemplo, es uno de los argumentos constantes al que aluden los varones entrevistados como factor de dependencia emocional que les hace muy difícil el abandono del domicilio conyugal:

“¿Y qué haces? Pues aguantar. (...). Las niñas no tienen ninguna culpa. Estuve aguantando hasta el mes de abril en que llegó un día que no pude más" (Alberto (20)).

"Ya no era cuestión de dejar a mi pareja, era cuestión de dejar un niño al que le has estado dando de comer, cambiando pañales... Psicológicamente afecta mucho" (Enric (21)).

En estas reflexiones de Alberto y Enric observamos la importancia de la paternidad como causa moral para permanecer en la relación violenta sino también las nuevas formas de afrontar una esfera que, hasta no hace tanto, era privativa de la mujer: el cuidado de los hijos/as. Enric alude a cómo el tiempo que dedicó al cuidado de su hijo creó unos vínculos para él muy importantes. Los varones españoles cada vez más asumen el cuidado de los hijos e hijas y pasan más tiempo con ellos (Caïs 2012). Por tanto, cuando los varones entrevistados ven agredida su identidad como padres se sienten atacados. Para los varones maltratados por su pareja, la paternidad constituye un elemento de reivindicación, en tanto que víctima afectiva, aceptado y comprendido socialmente. Desde el momento en que el varón es consciente de que la reivindicación de su paternidad crea solidaridad social, algunos de los entrevistados la usan como un primer elemento que les facilita la capacidad de expresión y comunicación pública de otros agravios.

\section{A modo de resumen}

Los sujetos objeto de estudio en este artículo se definen ellos mismos como casos excepcionales debido a que consideran que sus propias experiencias no encajan con las del imaginario colectivo español. La excepcionalidad de su relato tiene consecuencias en su (in)capacidad de expresión pública que viene 
condicionada por diversos aspectos que envuelven el fenómeno del varón maltratado en España: la invisibilización social y académica de estas situaciones, la vergüenza experimentada por estos varones al no adecuarse al ideal masculino de poder y control, y la necesidad de gestionar el temor a las posibles reaccionas burlescas con que se encuentran al relatar sus vivencias. Para superar estos condicionantes, los varones entrevistados intentan mostrar que no son un caso aislado; pero su estrategia principal es aludir a la defensa de la paternidad como elemento legitimador de la identidad masculina. Si tienen hijos con la mujer agresora muestran la necesidad de expresar públicamente sus casos como una reivindicación del ejercicio de una paternidad positiva.

Los varones entrevistados intentan legitimar su posición como víctima de maltrato por parte de su pareja. Estos varones reformulan el discurso de género para desmarcarse de los roles característicos de la masculinidad hegemónica. Los varones maltratados rechazan aquellos comportamientos socialmente mal vistos del "macho" que consideran que deslegitimarían su situación de "víctimas". Deben negociar el requisito de vulnerabilidad inherente a la definición institucional y social de "víctima" en el universo de la violencia en las relaciones de pareja y para ello utilizan los ataques que reciben en el ejercicio de su paternidad. Hemos encontrado también que los varones estudiados tienen dificultades para hablar de agresiones físicas sufridas ya que en sus relatos se usan evasivas y minimizaciones de su importancia. La negación de la importancia de la agresión física se relaciona con el control del dolor que creen que deben tener por el hecho de "ser hombre" ("no me sentí agredido porque no me hizo daño"). En cambio, se extienden en la expresión de su situación de víctima de violencia psicológica para definir su vulnerabilidad. El relato de violencia psicológica no es un elemento tan atacante a la masculinidad como puede ser la violencia física y apelan a la paternidad como condicionante principal de su vulnerabilidad al ligarles a una dependencia emocional con su pareja y obligarles a permanecer en el domicilio conyugal.

\section{Notas}

1. El lector puede encontrar la página completa en http://www.ahige.org -> "Historia". AHIGE cuenta ahora con 11 sedes en el territorio español: Andalucía, Canarias, Cantabria, Castilla La Mancha, Islas Baleares, La Rioja, Madrid, Murcia y País Vasco.

2. Las publicaciones del INE, Mujeres y Hombres en España, no ofrecen datos más allá de 2007 clasificadas como "denuncias por malos tratos en el ámbito familiar, según relación con el/la autor/a".

3. El lector puede encontrar el documental en su totalidad en http://www.tv3.cat/videos/1633989

\section{4. http://www.diariodemallorca.es/sucesos/2008/12/02/miedo-mujer/414941.html}

\section{5. http://www.diariodemallorca.es/sucesos/2009/02/05/mujer-licencia-pegarme/433089.html}

\section{6. http://www.diariodemallorca.es/sucesos/2012/01/08/hombre-terapia-maltratadas/734158.html}

7. El lector puede encontrar el video en su totalidad en https://www.facebook.com/video/video.php? $\mathrm{v}=30205411512992$

8. Varón de 43 años residente en Palma de Mallorca. Electricista. Un hijo. Afirma haber sufrido maltrato físico y psicológico, así como institucional. Su exmujer fue condenada "como autora de un delito de lesiones en el ámbito familiar... a la pena de 3 meses y 15 días de prisión... se la condena, además, a la prohibición de aproximarse a Ramón LI. C. o fomentar su encuentro ....". Dispone de un teléfono de localización para mujeres maltratadas. Su caso salió en los medios de comunicación de Mallorca (prensa escrita y televisión).

9. Varón de 37 años residente en Tarragona. Divorciado y con dos hijos. Responsable de delegación en una empresa del sector público. Afirma haber sufrido maltrato psicológico e institucional. Centra su discurso en las amenazas de denuncia de su ex mujer. Afirma haber denunciado su caso a la Policía sin obtener respuesta. 
10. Varón de 37 años residente en Barcelona, en el Baix Llobregat. Profesor de Instituto y de Ingenieria en la Universidad Politécnica de Cataluña. Ingeniero técnico. Divorciado y con dos hijas. Declara haber sufrido agresiones físicas, violencia psicológica e institucional. Su exmujer fue condenada por "autora de faltas de amenazas imponiéndole pena de seis meses y tres días de localización permanente". Dispone de la custodia compartida de las dos hijas.

11. Varón de 40 años residente en Girona, Baix Empordà. Vigilante de seguridad. Soltero con un hijo fruto de la relación con la mujer de la que afirma haber sufrido maltrato físico y psicológico. También ha entrado en litigios judiciales con su exmujer, cuyas consecuencias define como "violencia institucional". Dispone de una orden de alejamiento de su ex pareja por agresiones físicas recibidas.

12. Varón de 50 años residente en Barcelona y con dos hijos. Arquitecto. Su exmujer ha sido inculpada "como autora de un delito de lesiones en violencia familiar del artículo 153.2 CP LO 1/04" y condenada por ello a "las penas de tres meses de prisión, (...) y la pena accesoria de prohibición de comunicación por cualquier medio por un tiempo de un año y un día". Su caso ha salido en los medios de comunicación.

13. Varón de 37 años residente en Barcelona, en el Baix Llobregat. Profesor de Instituto y de Ingenieria en la Universidad Politécnica de Cataluña. Ingeniero técnico. Divorciado y con dos hijas. Declara haber sufrido agresiones físicas, violencia psicológica e institucional. Su exmujer fue condenada por "autora de faltas de amenazas imponiéndole pena de seis meses y tres días de localización permanente". Dispone de la custodia compartida de las dos hijas.

14. Varón de 40 años residente en Girona, Baix Empordà. Vigilante de seguridad. Soltero con un hijo fruto de la relación con la mujer de la que afirma haber sufrido maltrato físico y psicológico. También ha entrado en litigios judiciales con su exmujer las consecuencias de las cuáles define como "violencia institucional". Presidente de la "Asociación de Padres y Madres Separados" de Girona. Dispone de una orden de alejamiento de su ex pareja por agresiones físicas recibidas.

15. Varón de 67 años residente en Barcelona ciudad. Divorciado y con dos hijas. Arquitecto y profesor de universidad ahora jubilado. Afirma haber sufrido maltrato físico y psicológico por parte de su ex mujer así como maltrato institucional. Cuenta con 14 denuncias correspondientes a 22 procesos judiciales resueltos a su favor. Dispone de la custodia de su hija menor.

16. Varón de 44 años residente en Barcelona, Vallès Oriental. Soltero. Dos hijos. Un niño y una niña menores de edad. Pluriempleado en trabajos varios temporales. Afirma haber sufrido maltrato psicológico y reconoce agresiones físicas por parte de ambos miembros de la pareja. Estuvo en prisión por denuncia de violencia de género.

17. Varón de 37 años residente en Barcelona, en el Baix Llobregat. Profesor de Instituto y de Ingenieria en la Universidad Politécnica de Cataluña. Ingeniero técnico. Divorciado y con dos hijas. Declara haber sufrido agresiones físicas, violencia psicológica e institucional. Su exmujer fue condenada por "autora de faltas de amenazas imponiéndole pena de seis meses y tres días de localización permanente".

18. La transcripción literal del relato de uno de los episodios de agresión física que afirma haber sufrido contextualiza este ejemplo: "Los gritos y amenazas de Marta fueron en aumento hasta que aquí, en la cocina, me..., me... bueno, es cuando me puso la mano encima. La primera vez. Insultos y broncas eran a diario pero ese día...".

19. Varón de 54 años residente en Barcelona, centro ciudad. Divorciado y con un hijo. Director de una empresa aseguradora. Afirma haber sufrido maltrato psicológico por parte de su exmujer e institucional. Centra su discurso en el proceso de sumisión que afirma haber sufrido durante la relación con su ex mujer y en las consecuencias personales y económicas que han derivado de ello.

20. Varón de 37 años residente en Barcelona, en el Baix Llobregat. Profesor de Instituto y de Ingenieria en la Universidad Politécnica de Cataluña. Ingeniero técnico. Divorciado y con dos hijas. Declara haber sufrido agresiones físicas, violencia psicológica e institucional. Su exmujer fue condenada por "autora de faltas de amenazas imponiéndole pena de seis meses y tres días de localización permanente".

21. Varón de 40 años residente en Girona, Baix Empordà. Vigilante de seguridad. Soltero con un hijo fruto 
de la relación con la mujer de la que afirma haber sufrido maltrato físico y psicológico. También ha entrado en litigios judiciales con su exmujer, cuyas consecuencias define como "violencia institucional". Presidente de la "Asociación de Padres y Madres Separados" de Girona. Dispone de una orden de alejamiento de su ex pareja por agresiones físicas recibidas.

\section{Bibliografía}

Anzieu, Didier

1981 "La réalité imaginaire des groupes", en Didier Anzieu (ed.), Le groupe et linconscient. París, Dunod: 25-66.

Badinter, Elisabeth

1993 XY La identidad masculina. Madrid, Alianza Editorial.

Best, Deborah L.

2004 "Gender Stereotypes", en Carol. R. Ember y Melvin Ember (eds.), Encyclopedia of Sex and Gender: Men and Women in the World's Cultures. USA, Springer: 11-27.

Boletín Oficial del Estado

2004 "Ley Orgánica 1/2004, de 28 de diciembre, de Medidas de Protección Integral contra la Violencia de Género", Jefatura del Estado, BOE, 313, 42.166-42.197.

https://www.boe.es/buscar/doc.php?id=BOE-A-2004-21760.

Caïs, Jordi

2012 "Familia, treball remunerat i dinàmiques de relació intergeneracional: temps i activitats compartides", en Carme Gómez-Granell y Pau Marí-Klose (eds.), Infància, Adolescència i Família: un anàlisi del Panel de Famílies i Infància. Barcelona, CIIMU (Institut d'Infància i Món Urbà): 20-61.

Caïs, Jordi (y Laia Folguera)

2013 "Redefining the Dynamics of Intergenerational Family Solidarity in Spain", European Societies, $n^{\circ} 15$ (4): 557-576.

Cook, Philip W.

1997 Abused Men: The Hidden Side of Domestic Violence. New York, Praeger Publishers.

Dowd, Lynn

2001 "Female Perpetrators of partner Agression", Journal of Aggression, Maltreatment and Trauma, $\mathrm{n}^{\circ} 5$ (2): 73-104.

Durfee, Alesha

2011 "I'm Not a Victim, She's an Abuser: Masculinity, Victimization, and Protection Orders", Gender \& Society, $\mathrm{n}^{\circ} 25: 316-333$.

Dutton, Donald G.

1988 "Profiling of Wife Assaulters: Preliminary Evidence for a Trimodal Analysis", Violence and Victims (New York), nº 3 (1): 5-29.

Dutton, Donald G.

2007 "Female Intimate Partner Violence and Developmental Trajectories of Abusive Families", International Journal of Men's Health (Harriman, USA), nº 6 (1): 54-71.

Edleson, Jeffrey L. (y Mary Pat Brygger)

1986 "Gender differences in reporting of battering incidents", Family Relations (Malden, USA), n 35: 377 382. 
Farrell, Warren

1994 The Myth of Male Power. New York: Berkley Books.

Fiebert, Martin S. (y Denise M. González)

1997 "College Women who Initiate Assaults on their Male Partners and the Reasons Offered for Such Behaviour", Psychological Reports (Missoula, Montana), n 80: 583-590.

Gelles, Richard J.

1974 The Violent Home: A Study of Physical Aggression Between Husbands and Wives. California, Sage.

George, Malcolm J.

1994 "Riding the donkey backwards: Men as the unacceptable victims of marital violence", Journal of Men's Studies (Harriman, USA), nº 3 (2): 137-159.

George, Malcolm J.

2007 'The 'Great Taboo' and the Role of Patriarchy in Husband and Wife Abuse", International Journal of Men's Health (Harriman, USA), $n^{\circ} 6$ (1): 7-22.

Gil Calvo, Enrique

1997 El nuevo sexo débil: Los dilemas del varón posmoderno. Madrid, Temas de Hoy.

Gilmore, David D.

1990 Manhood in the Making: Cultural Concepts of Masculinity. London, Yale University Press.

Graham-Kevan, Nicola

2007 "The re-emergence of male victims", International Journal of Men's Health (Harriman, USA), nº (1): 36.

Gregorash, Lesley

1993 Family Violence: An Exploratory Study of Men Who Have Been Abused by Their Wives. Alberta (Canadá), University of Calgary.

Guasch, Oscar

2006 Héroes, científicos, heterosexuals y gays: los varones en perspectiva de género. Barcelona, Edicions Bellaterra.

Hines, Denise A. (y Kathleen Malley-Morrison)

2001 "Psychological effects of partner abuse against men: A neglected research area", Psychology of Men and Masculinity (Washington), $\mathrm{n}^{\circ} 2: 75-85$.

Instituto de la Mujer

2006 III Macroencuesta sobre la violencia hacia las mujeres. Madrid, Ministerio de Trabajo y Asuntos Sociales.

Instituto Nacional de Estadística

2008 Mujeres y hombres en España 2009. Madrid, INE.

Instituto Nacional de Estadística

2009 Mujeres y hombres en España 2009. Madrid, INE.

Jodelet, Denise

1984 "The Representations of the Body and its Transformations", en Robert Farr y Serge Moscovici (ed.), Social Representations. Cambridge, Cambridge University Press: 211-238.

Lewis, Helen B.

1971 Shame and Guilt in Neurosis. New York, International University Press.

Lynd, Helen Merrell

1958 On Shame and the Search for Identity. New York, Harcourt Brace. 
Marshall, Linda L.

1992 “The Severity of Violence against Men Scales”, Journal of Family Violence, nº 7 (3): 189-203.

McLeod, Maureen

1984 "Women Against Men: An Examination of Domestic Violence Based on an Analysis of Official Data and National Victimization Data", Justice Quarterly, no 1: 171-193.

Meil Landwewrlin, Gerardo

2006 Pares i fills a l'España actual. Barcelona, Fundació la Caixa.

Morse, Barbara J.

1995 "Beyond the Conflict Tactics Scale: Assessing Gender Differences in Partner Violence", Violence and Victims, $n^{\circ} 10$ (4): 251-272.

O'Connal, Jason

2006 The War Against Men Has Been Declared. Australia, Scribd.

Pitt-Rivers, Julian

1965 Honor and Shame: The Values of Mediterranean Society. Chicago, Chicago University Press.

Prades, Joaquina

2012 "Pocos, pero también víctimas", El País (Madrid), 10 de junio.

http://sociedad.elpais.com/sociedad/2012/06/09/actualidad/1339261089 947487.html.

Sarasa, Sebastian (y Sunnee Billingsley)

2008 "Personal and Household Care Giving from Adult Children to Parents and Social Stratification", en

Chiara Saraceno (ed.), Families, Aging and Social Policy. Cheltenham, U.K, Edward \& Elgar: 123-146.

Scheff, Thomas J.

2003 “Male Emotions/Relationships and Violence: A Case Study”, Human Relations, n 56 (6): 727-749.

Sommer, Reena

1994 Male and Female Perpetrated Abuse: Testing a Diathesis-Stress Model. Canada, Phd Thesis.

Steinmetz, Suzanne

1977 "The Battered Husband Syndrome”, Victimology, n² 2 (3): 499-509.

Stets, Jan E. (y Murray A. Straus)

1990 "Gender Differences in Reporting of Marital Violence and its Medical and Psychological Consequences", en Murray A. Straus y Richard J. Gelles (eds.), Physical Violence in American Families, Risk Factors and Adaptations to Violence in 8.145 Families. New Brunswick, NJ, Transaction Publishers: 151-165

Straus, Murray A. (y otros)

1980 Behind Close Doors: Violence in American Family. New York, Anchor Books.

Straus, Murray A.

1999 "The Controversy Over Domestic Violence by Women: A Methodological, Theoretical, and Sociology of Science Analysis", en Arriaga Stuart Oskamp (ed.), Violence in intimate relationships. Thousand Oaks, CA, Sage: $17-44$. 